differ markedly from the sudden advances found in our other experiments in that there was no lag period, and a much higher proportion of tho lines showed an advance which, in some instances, was greater than over reached before. Less than 10 per cent of all the previous linos solocted from line 70 showed a sudden response after a lag of 5-10 gonorations. The control selections from line 70 established in parallel with tho present experiments havo shown no sudden advances by the seventh generation in 30 linos; a most striking contrast.

A probable explanation of these results is that restriction of variability to one chromosome was offective, by eliminating interactions, in exposing additive genetic variability, thus onabling selection to eause greater and more rapid response. An alternative explanation might be that the use of isogenic $5 a-8$ had introduced a particular pattern of interaction, normally rare in line 70 , that made response possible. We favour the first explanation, but clearly this typo of oxperiment needs to be repoatod on different isogenic backgrounds including that of line 70 .

RAJA NASSAR

Department of Animal Husbandry,

Institute of Agriculture,

St. Paul, Minnesota.

Aleix Fraser

Genetics Department,

University of California, Davis.

1 Mather, K., J. Genet., 41, 159 (1941).

2 Payne, F,, Indiana Univ, Studies, 36, 1 (1918).

s Sismanidis, A., J. Genet., 44, 204 (1942).

- 'Ihoday, J. M., and Boam, T. B., Genet. Res., 2, 161 (1961).

${ }^{5}$ Fraser, A. S., and Hansche, P. E., Genetics Today, 2 (Pergamon Press, London, 1964).

${ }^{6}$ Clayton, G. A., Morris, J. A., and Robertson, A., J. Genet., 55, 131 (1957).

\section{Further Evidence of Heterozygosity in Parthenogenetic Turkeys}

IT has boon reported that first and second sot skin grafts from parthenogenetic Boltsville Small White turkey sircs to some of their progeny by unrelated turkey females are rejected by typical homograft reactions. The finding that skin from any one parthenogenetic sire can bo compatible with some of his progony and incornpatible with others was interpreted as evidence of segregation having occurred at one or more of his genetic loci assumed to control histocompatibility. On this basis it was concluded that a detectable degree of heterozygosity can exist in male turkey parthenogens ${ }^{1}$.

Howover, this conclusion prompted the question that since the parthenogens' dams were not the darns of the recipient progeny the graft rojections might have been an expression of some sort of 'maternal effect'. The validity of this point was appraised by the following experiment.

Two male parthenogenetic turkeys ( $P-2789$ and $P-386)$ were mated each to his own dam and produced seven and four progeny respectively. Thoso are hereafter called back-cross progony, and each of them received a fullthickness wattle skin graft from its own parthenogenetic sirc. The only variation from previously published surgical procodures ${ }^{1,2}$ was in the method of bandaging. Hero, rather than usc a cotton bolus, we protected the sutured graft with a layer of spray-on plastic surgical dressing followed by a piece of petrolatum gauze, and finally a loosely applied gauze pad.

The skin of P.2789 was found to be compatible with three and incompatiblo with four of his back-cross progeny, while the skin of $P-386$ was compatible with two and incompatiblo with two of his back-cross progeny.

In view of these results it is hard to conceive how the graft rejections in tho previously published work ${ }^{1}$ could be accounted for on the basis of the parthenogenetic sires and their progeny having had different maternal parents. Instead, they strongly support the former conclusion that parthenogens can be heterozygous at one, at least, of the segregating genetic loci assumed to control histocompatibility in turkoys.

I thank Dr. M. W. Olsen for providing the turkeys for this study.

H. K. PooLe

United States Department of Agriculture,

Animal Husbandry Rosearch Division, Beltsville, Maryland.

' Poole, H. K., Healey, W. V., Russell, P. S., and Olsen, M. W., Proc. Soc. Exp. Biol. and Med., 1is, b03 (1903). ${ }^{2}$ Healey, W. V., Russell, P. S., Poole, H. K., and Olsen, M. W., Ann. N.Y.
Acad. Sci., 99, 698 (1962).

\section{Non-independent Occurrence of $\alpha_{8_{1}}$ and $\beta$-Casein Variants of Cow's Milk}

I'He $\beta$-casein fraction of cow's milk has been found to show gonetic variants distinguishable by olectrophoresis ${ }^{1}$. Part of the $\alpha_{\delta}$-casoin fraction, now called $\alpha_{\delta_{1}}$-casein (ref. 2), also shows genetic variations. The $\alpha_{s_{1}}$-casein type $B$ and the $\beta$-cascin type $A$ are prevalent, while the other two known variants of each only occur in some breeds of cattle $\theta^{4,5}$. In Jersey cows $\alpha_{8_{1}}$-casein type $O$ and $\beta$-casein type $B$ are seen in a fair proportion of casos.

Examination of tho results of typing one herd of British Jerseys suggested that the $\alpha_{s_{1}}$ and $\beta$-variants did not occur independently and this trend was confirmed by more numerous data for British and American Jersoys. Tho pooled rosults for all availablo cows (not a random sample of the breed) gave the following pattern of occur. rence:

\begin{tabular}{ccccc} 
& & & $\beta$-casein & \\
& & $A$ & $A B$ & $B$ \\
\multirow{4}{*}{$a_{s_{1}}$-casein } & $B$ & 60 & 73 & 56 \\
& $B C$ & 45 & 82 & - \\
& $C$ & 35 & - & -
\end{tabular}

The joint distribution shows a complete absonce of three combinations of types. Based on expectations derivod from the marginal totals of the above table, the absence of these threo classes is judged to be highly significant and extremely unlikely to be due to chance $(P<0.00001)$.

Pooled data for Guernsey cattle typed in Britain and the United States were arranged in the same manner.

$$
\begin{array}{cccccc} 
& & \multicolumn{4}{c}{\beta \text {-casein }} \\
& & A & A B & A C & C \\
\alpha_{81} \text {-cascin } & B & 85 & 5 & 11 & 1 \\
& B C & 52 & 2 & 5 & =
\end{array}
$$

The absenco of certain combinations is noticeable, although the expectation of observations in these classes is hero small. A similar picture was found for American Brown Swiss cows;

$$
\begin{array}{llrrrr} 
& & \multicolumn{4}{c}{\beta \text {-casein }} \\
& & A & A B & B & A C \\
a_{81} \text {-casein } & B & 146 & 69 & 4 & 2 \\
& B C & 22 & -5 & - & -
\end{array}
$$

Hero again the absonce of some classes could easily bo ascribed to chance, but the similarity to the othor rosults suggests that this is not the explanation.

Evidenco has been produced to show that both $\alpha_{s_{1}}$ and $\beta$-casein variants are inhorited in a straightforward Mendelian manner ${ }^{1,3}$. The loci have been designated $\alpha_{s_{1}}-O n$ and $\beta-C n$. The present finding that the two kinds of variants do not occur independently suggests that the two loci may be linked, and in the Jerscy breed, for example, the following chromosomes would be postulated: $\alpha_{8_{1}}$.

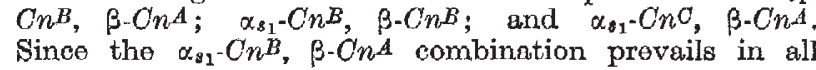

